\title{
Concentrations and Composition Profiles of Benzotriazole UV Stabilizers in Municipal Sewage Sludge in China
}

\author{
Ting Ruan, ${ }^{\dagger}$ Runzeng Liu, ${ }^{\dagger}$ Qiang Fu, ${ }^{\dagger}$ Thanh Wang, ${ }^{\dagger}$ Yawei Wang, ${ }^{\dagger}$ Shanjun Song, ${ }^{\dagger}$ Pu Wang, ${ }^{\dagger}$ \\ Man Teng, ${ }^{\ddagger}$ and Guibin Jiang*, ${ }^{\dagger}$
}

${ }^{\dagger}$ State Key Laboratory of Environmental Chemistry and Ecotoxicology, Research Center for Eco-Environmental Sciences, Chinese Academy of Sciences, Beijing 100085, China

¥China National Environmental Monitoring Center, Beijing 100029, China

\section{Supporting Information}

\begin{abstract}
The environmental contamination and fate of benzotriazole UV stabilizers (BZTs) have received increasing attention due to their large production volume and wide usage in various consumer and industrial products. In the present work, 60 municipal sewage sludge samples from wastewater treatment plants (WWTPs) in 33 cities in China were collected to investigate the occurrence and distribution of 9 frequently used BZTs. The most dominant analogue was 2[3,5-bis (1-methyl-1-phenylethyl)-2-hydroxyphenyl]benzotriazole (UV-234) at a median concentration of $116 \mathrm{ng} /$ $\mathrm{g}$ (dry weight) and accounted on average for $27.2 \%$ of total

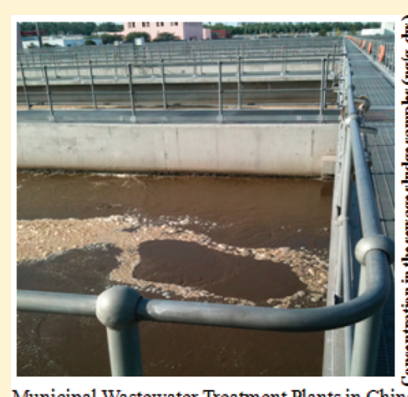

Municipal Wastewater Treatment Plants in China

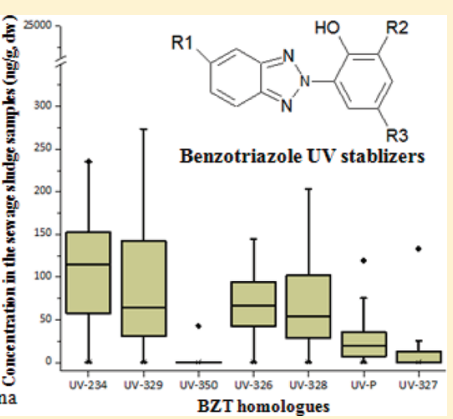

BZTs. The abundance was successively followed by $2-(2-$

hydroxy-5-tert-octylphenyl)benzotriazole (UV-329, average 24.3\%), 2-(2-hydroxy-3-tert-butyl-5-methylphenyl)-5-chlorobenzotriazole (UV-326, average 22.2\%), 2-(3,5-di-tert-amyl-2-hydroxyphenyl)benzotriazole (UV-328, average 17.7\%), and 2-(2hydroxy-5-methylphenyl)benzotriazole (UV-P, average 6.6\%), with median concentrations of 66.8, 67.8, 57.3, and 20.6 ng/g, respectively. 5-Chloro-2-(3,5-di-tert-butyl-2-hydroxyphenyl)benzotriazole (UV-327) and 2-(3-sec-butyl-5-tert-butyl-2hydroxyphenyl)benzotriazole (UV-350) had low detection frequency, while 2-(3,5-di-tert-butyl-2-hydroxyphenyl)benzotriazole (UV-320) and 2-(5-tert-butyl-2-hydroxyphenyl)benzotriazole (UV-PS) were not detectable in any sample. To our knowledge, this is the first study reporting the occurrence of UV-234, UV-329, and UV-350 in sewage sludge in China. Significant correlations were found among the BZT concentrations and also with a WWTP characteristic (daily treatment volume). Furthermore, results from degradation prediction and multimedia fate simulation based on a quantitative structure-property relationship (QSPR) model at screening level also implied that the commercial BZT chemicals and their plausible transformation products might be persistent in the environment.
\end{abstract}

\section{INTRODUCTION}

The occurrence and fate of a vast majority of new anthropogenic chemicals with wide commercial applications have received increasing attention in the past decades, mainly due to the lack of information regarding their potential environmental fate and toxicological effects. ${ }^{1-3}$ National and international programs, for example, the High Production Volume (HPV) chemical programs by the U.S. EPA ${ }^{4}$ and the Organization for Economic Co-operation and Development (OECD $),{ }^{5}$ have been established to face the challenges of chemical assessment and management. Among the HPV chemicals, an increasing awareness has been raised to the socalled UV stabilizers, which are used widely both in daily commodities and industry products to adsorb ultraviolet radiation from sunlight. ${ }^{6-8}$ Some of the most widely applied chemicals, such as oxybenzone and benzophenone derivatives, have been frequently detected at concentrations ranging from part-per-trillion (ppt) to part-per-million (ppm) in natural waters, soil, and sludge samples. ${ }^{9-14}$ Elevated concentrations of benzophenone-3 (BP-3), 4-methylbenzylidenecamphor (4$\mathrm{MBC}$ ), and octocrylene (OC) were also found in biota such as fish tissues and human blood and urine samples. ${ }^{10,15}$ Benzophenone derivatives have also been paid particular attention for their estrogenic and antiandrogenic effects in in vitro bioassays and in vivo studies. ${ }^{16,17}$

In this study, we focused the attention on benzotriazole UV stabilizers (herein abbreviated as BZTs, shown in Figure 1), also normally referred to as Tinuvins, which constitute one of the most important families of UV adsorbents. ${ }^{18}$ These (2hydroxyphenyl)benzotriazole derivatives are produced in large volumes and usually incorporated in various building materials, automobile polymeric components, waxes, films, and varnishes to prevent yellowing and degradation reactions by ultraviolet

Received: September 26, 2011

Revised: January 10, 2012

Accepted: January 13, 2012

Published: January 13, 2012 


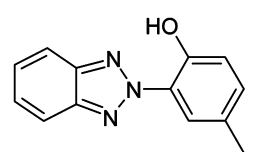

2-(2-hydroxy-5-methylphenyl)benzotriazole

(UV-P, 2240-22-4)

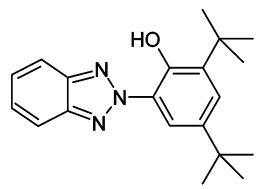

2-(3,5-di- tert -butyl-2-hydroxyphenyl)benzotriazole (UV-320, 3846-71-7)

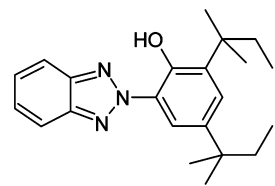

2-(3,5-di-tert-amyl-2-hydroxyphenyl)benzotriazole (UV-328, 25973-55-1)

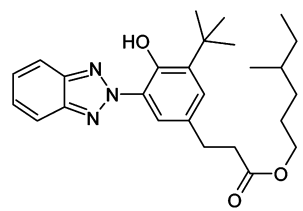

3-(2H-benzotriazolyl)-5-(1,1-dimethylethyl)-4-hydroxy-benzenepropanoic acid octyl esters

(UV-384, 127519-17-9)

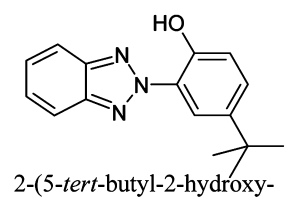

phenyl) benzotriazole

(UV-PS, 3147-76-0)

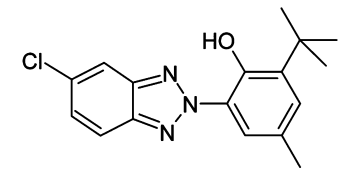

2-(2-hydroxy-3-tert-butyl-5-methylphenyl)-5-chlorobenzotriazole

(UV-326, 3896-11-5)

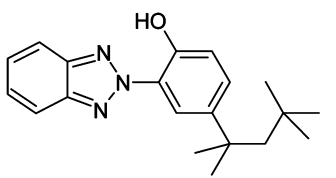

2-(2-hydroxy-5-tert-octylphenyl)benzotriazole (UV-329, 3147-75-9)

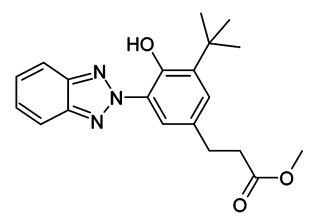

3-(2H-benzotriazolyl)-5-(1,1-dimethylethyl)-4-hydroxy-benzenepropanoic acid methyl ester

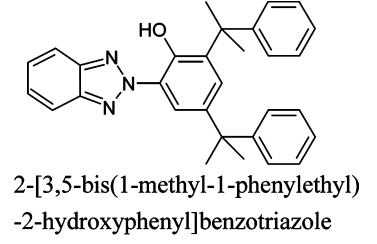

(UV-234, 70321-86-7)

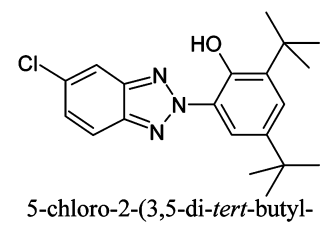

2-hydroxyphenyl)benzotriazole (UV-327, 3864-99-1)

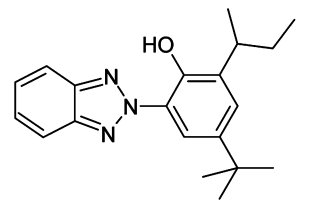

2-(3-sec-butyl-5-tert-butyl2-hydroxyphenyl)benzotriazole (UV-350, 36437-37-3)

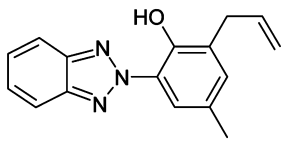

2-(3-allyl-2-hydroxy-5methylphenyl)-benzotriazole (Allyl-bzt, IS, 2170-39-0)

Figure 1. Chemical name, acronym, CAS Registry Number, and structure of benzotriazole analogues.

radiation from sunlight in the 320-400 nm (UV-A) and 280$320 \mathrm{~nm}$ (UV-B) bands. ${ }^{19,20} \mathrm{~A}$ few investigations indicated that certain benzotriazole derivatives, such as 2-(2-hydroxy-5methylphenyl)benzotriazole (UV-P, Figure 1), 2-(3-tert-butyl2-hydroxy-5-methylphenyl)-5-chlorobenzotriazole (UV-326), 5-chloro-2-(3,5-di-tert-butyl-2-hydroxyphenyl)benzotriazole (UV-327), and 2-(3,5-di-tert-amyl-2-hydroxyphenyl)benzotriazole (UV-328), are present in indoor dust, ${ }^{18}$ sewage sludge, ${ }^{20}$ and marine sediment at urban estuaries. ${ }^{19,21}$ Multiresidue surveys implied that these pollutants could be transported through aquatic systems and be bound in sedimentary deposits. ${ }^{22,23}$ This group of compounds has also been found to be magnified though trophic levels in wildlife. ${ }^{19,24,25}$

Previous work has found that direct contact with a UV-Ptreated surface might cause dermatitis and skin irritation problems. $^{26}$ Median lethal doses $\left(\mathrm{LD}_{50}\right)$ of UV-327 were reported at $>25.0 \mathrm{mg} / \mathrm{L}$ in fish and $>2000 \mathrm{mg} / \mathrm{kg}$ in rat. ${ }^{19}$ Significant gender-related hematological and histopathological changes in liver, kidney, thyroid, and spleen were observed following long-term repeat-dose toxicity studies of 2-(3,5-ditert-butyl-2-hydroxyphenyl)benzotriazole (UV-320) in rats, which might be associated with differences in the hepatic peroxisome proliferative activity between the sexes. ${ }^{27}$ Similar repeat-dose toxicity effects have also been found for UV-328 and the no observable adverse effect level (NOAEL) was reported to be $<15 \mathrm{mg} / \mathrm{kg}$, with liver as the most sensitive organ. ${ }^{28}$ Ecotoxicological studies for BZT UV stabilizers have also been conducted on aquatic invertebrate model animals. The 24-h half-maximal effective concentration $\left(\mathrm{EC}_{50}\right)$ of 2-(2hydroxy-5-tert-octylphenyl)benzotriazole (UV-329) was 15 $\mathrm{mg} / \mathrm{L}$ for Daphnia magna, ${ }^{29}$ and the median lethal concentrations $\left(\mathrm{LC}_{50}\right)$ of many frequently used BZTs were reported to be $>10 \mathrm{mg} / \mathrm{L}$ for freshwater crustacean. ${ }^{30}$

Similar to other hydrophobic substances, the environmental concentrations of benzotriazole UV compounds are usually associated with organic matter such as suspended particulate matters and sedimentary sludge. ${ }^{14,31}$ Previous literature has reported that aromatic UV filters, such as 4-MBC and OC, were detected at relatively high concentrations in sewage sludge from wastewater treatment plants (WWTPs), indicating WWTPs are a major source of these chemicals in the aquatic environment. ${ }^{32-34}$ In the present work, we collected municipal sewage sludge from different Chinese cities, in order to provide valuable information of the contamination levels, distribution patterns, and potential sources of BZTs in the ambient environment in China. To our knowledge, this is the first work to report the presence of 2-(2-hydroxy-5-tertoctylphenyl)benzotriazole (UV-329), 2-[3,5-bis(1-methyl-1phenylethyl)-2-hydroxyphenyl]benzotriazole (UV-234) and 2(3-sec-butyl-5-tert-butyl-2-hydroxyphenyl)benzotriazole (UV350) in sewage sludge in China. 


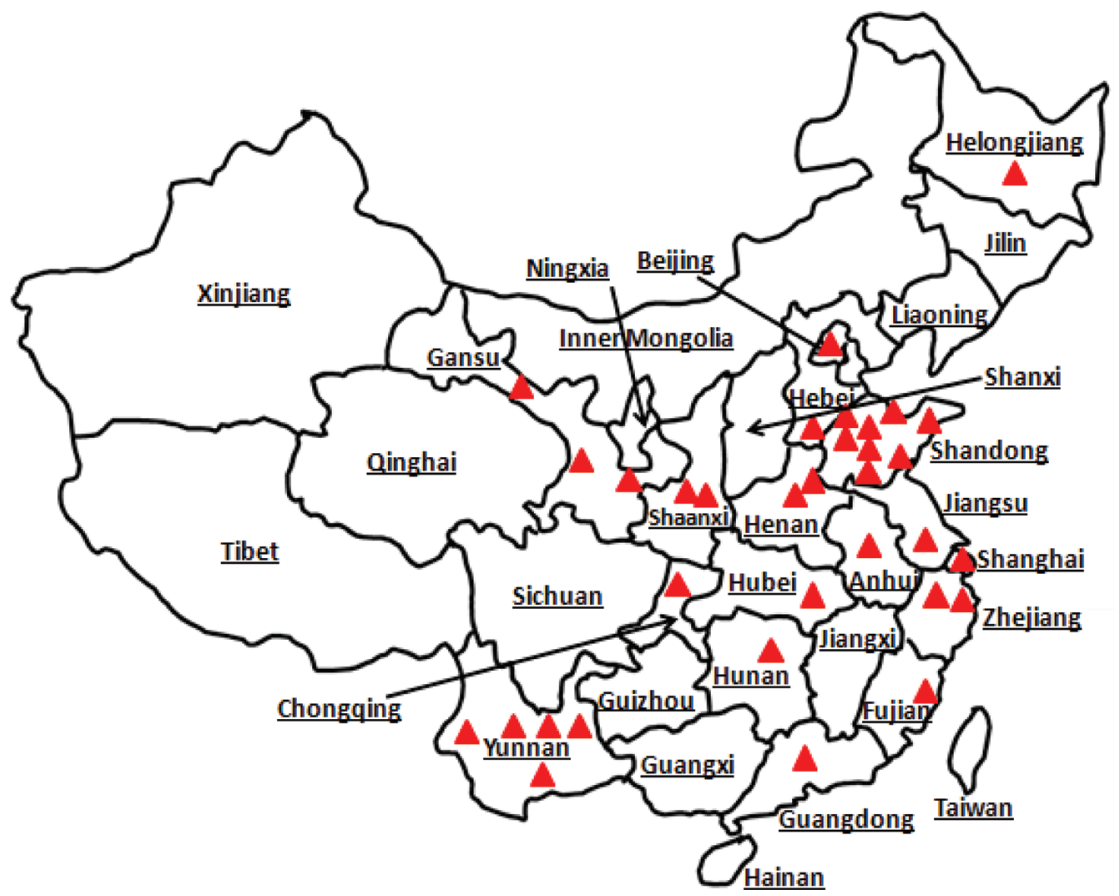

Figure 2. Sampling locations of municipal sewage sludge samples and total benzotriazole concentrations in China.

\section{MATERIALS AND METHODS}

Materials. Chemical structure and abbreviations are shown in Figure 1. UV-P (purity 99\%), UV-PS (98\%), UV-326 (98\%), UV-327 (98\%), UV-328 (98\%), UV-329 (98\%), and UV-350 (97\%) were purchased from TCI (Tokyo, Japan). UV-234 (99\%) and internal standard (IS, Allyl-bzt, 99\%) were obtained from Sigma-Aldrich (St. Louis, MO). UV-320 (99\%) was purchased from Dr. Ehrenstorfer (Augsburg, Germany). HPLC-grade methanol was supplied by J.T. Baker (Phillipsburg, NJ), and pesticide residue grade hexane and dichloromethane were obtained from Fisher Scientific (Hampton, NH). Ultrapure water $(18.3 \mathrm{M} \Omega)$ was generated by a Milli-Q system (Millipore, Billerica, MA).

Sample Collection. The sampling map and sites are shown in Figure 2. From October 2010 to February 2011, a total of 60 sewage sludge samples were collected from different municipal WWTPs in 33 cities, most of which are located in economically developed provinces in China. Freshly digested sludge samples (approximately $500 \mathrm{~g}$ of wet weight for each sample) were collected at the dewatering process, packed in aluminum foil, sealed in polypropylene bags, and then immediately expressdelivered to our laboratory and kept at $-20{ }^{\circ} \mathrm{C}$ until analysis. A questionnaire was completed for each sludge sample, regarding the treatment processing volume, sources of the sewage, type of treatment, and drying operations. Detailed information is given in the Supporting Information (Table S2).

Sample Pretreatment and Quantitative Analysis. All sludge samples were freeze-dried, homogenized, and sieved through a stainless steel 100 -mesh sieve. The sample pretreatment procedure is similar to previously reported methods with slight modifications. ${ }^{18,19}$ In brief, approximately $1 \mathrm{~g}$ of sample was mixed with $15 \mathrm{~g}$ of anhydrous sodium sulfate and extracted with hexane/dichloromethane $(7: 3, \mathrm{v} / \mathrm{v})$ at $90^{\circ} \mathrm{C}$ and $1500 \mathrm{psi}$ in three static extraction cycles of $10 \mathrm{~min}$ using an accelerated solvent extractor (ASE 350, Dionex Inc., Sunnyvale, CA). The extract was concentrated by rotary evaporation to $\sim 2 \mathrm{~mL}$ and fractioned on a Biobeads S-X3 (Bio-Rad Laboratories, Hercules,
CA) gel permeation chromatography column (GPC, $400 \times 30$ $\mathrm{mm}$, i.d.). A 1:1 hexane/dichloromethane mixture (v/v) was eluted at a flow rate of $5 \mathrm{~mL} / \mathrm{min}$, and a second fraction of 120 $\mathrm{mL}$ was collected after discarding the first $110 \mathrm{~mL}$ of eluate. The solvent was then concentrated and passed through an $8 \mathrm{~g}$ Florisil column (60-100 mesh, Sigma-Aldrich, St. Louis, MO), which was activated at $140{ }^{\circ} \mathrm{C}$ for $7 \mathrm{~h}$ and $5 \%$ water-deactivated prior to use. The column was first preconditioned by $30 \mathrm{~mL}$ of hexane and all analytes were eluted with $50 \mathrm{~mL}$ of 1:1 hexane/ dichloromethane mixture. Finally, analytes were concentrated, solvent exchanged into $1 \mathrm{~mL}$ of methanol spiked with $100 \mathrm{ng}$ of internal standard (IS), and $20 \mu \mathrm{L}$ of the final extract was injected into the instrument for quantification analysis.

An Alliance 2695 high-performance liquid chromatography interfaced with a Quattro Premire XE triple-quadrupole mass spectrometer (HPLC-MS/MS, Waters Inc., Milford, MA) was used for the instrumental analysis. A $150 \times 4.6 \mathrm{~mm}$ SymmetryShield $5 \mu \mathrm{m} \mathrm{C18}$ analytical column was chosen for separation. Column temperature was set as $40{ }^{\circ} \mathrm{C}$ and flow gradient was initiated at a composition of 8:2 (methanol/water, $\mathrm{v} / \mathrm{v}$ ) with a flow rate of $1 \mathrm{~mL} / \mathrm{min}$ and then linearly increased to $100 \%$ methanol in $20 \mathrm{~min}$. Atmospheric pressure chemical ionization (APCI) was operated in the positive mode with equipment resolution tuned to $0.7 \mathrm{amu}$ full-width halfmaximum. The corona current was set as $3.0 \mu \mathrm{A}$, and source and APCI probe temperatures were optimized at 110 and 550 ${ }^{\circ} \mathrm{C}$, respectively. Desolvation gas flow was $150 \mathrm{~L} / \mathrm{h}$ and argon pressure for ion collision was kept at $3.8 \times 10^{-3} \mathrm{mbar}$. Detailed monitoring parameters for each of the analyte are given in the Supporting Information (Table S1).

Quality Assurance/Quality Control. For the positive identification and quantification of the analytes, confirmation criteria given elsewhere was use for the analysis. ${ }^{35}$ Briefly, the relative retention time of the analytes should match that of the calibration standards at a tolerance of $1.0 \%$. A signal-to-noise ratio of 10:1 was a requisite for positive identification. The ratio of the quantification to the confirmation ions in real samples 
should be within $20 \%$ of that in the standards. The recoveries of matrix spiked samples (100 ng/g in sludge for all the analytes, mean \pm standard deviation) ranged from $83 \pm 11 \%$ (UV-350) to $100 \pm 9 \%$ (UV-328), with a mean of $93 \%$. The recovery of matrix matched spikes of IS (100 ng/g sludge) in real samples were in the range of $96 \pm 8 \%$, indicating that Allyl-bzt was not present or occurred at insignificant concentrations in the sewage sludge and thus could be used as an appropriate internal standard. Before use, all glassware was thoroughly rinsed with dichloromethane. One procedural blank of $15 \mathrm{~g}$ of solventwashed anhydrous sodium sulfate was included for each batch of seven samples. Most of the analytes in the blanks were under the detection limit, except for UV-326, which contributed to between 0 and $13 \%$ of average concentrations in each batch of samples. Thus, UV-326 concentrations were subtracted for blank contamination, while recoveries were not corrected. The method quantification limits (MQLs), calculated as a signal-tonoise ratio of 10, were from 0.15 (UV-234) to 0.77 (UV-320) $\mathrm{ng} / \mathrm{g}$ sludge (dry weight, $\mathrm{dw}$ ) and the linear dynamic range was $1-200 \mathrm{ng} / \mathrm{g}$ for all the analytes.

Statistical Analysis. Principal component analysis (PCA), Pearson's correlation, and GH biplot analysis were conducted using SPSS V13.0 for Windows Release (SPSS Inc., 2004) and Stata package V11.1 (StataCorp, 2009). BZT proportions were centered log-ratio transformed as mentioned elsewhere in order to remove intrinsic constraints of closure. ${ }^{36}$ Nondetects were treated as half MQL, and UV-350 was excluded in the statistics analysis due to its low detection frequency. PCA was performed using the varimax rotation method with Kaiser normalization and all the statistical significant levels were set at $p<0.05$, unless otherwise mentioned.

\section{RESULT AND DISCUSSION}

Analogue Concentrations and Composition Profiles in Sludge. Spatial concentrations of BZTs in the sewage sludge are presented in Figure 3 and the Supporting

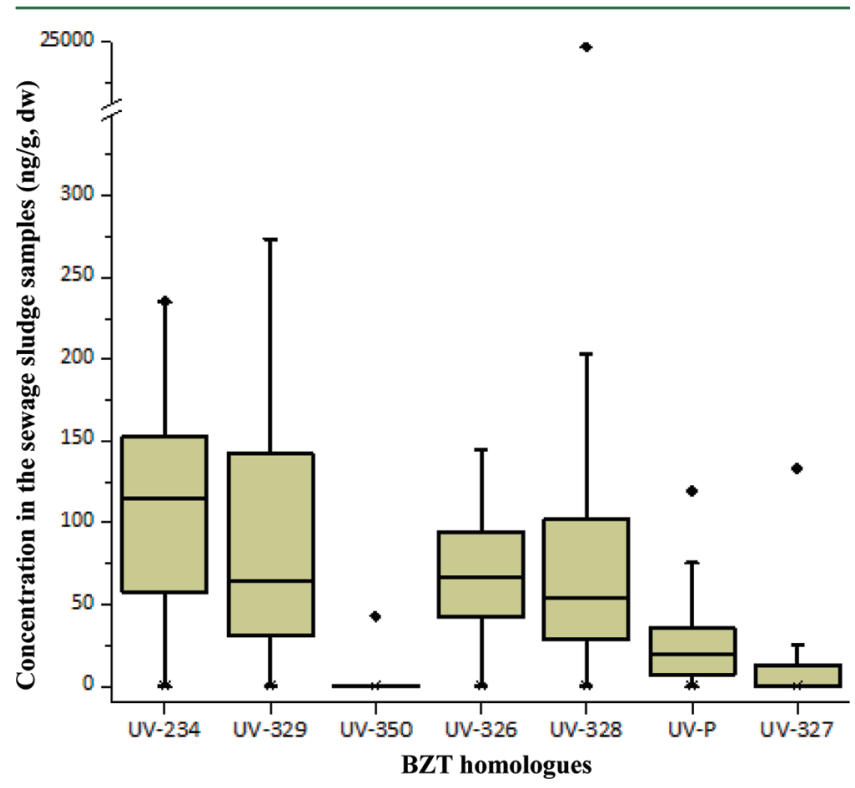

Figure 3. Concentrations of detected benzotriazole analogues in the sewage sludge samples. The lines represent the 5th, 50th, and 95th percentiles; the boxes represent the 25 th -75 th percentiles; $>$ and $*$ represent the concentration range of $99 \%$ and $1 \%$, respectively. Nondetects were set as half MQL for each BZT analogue.
Information (Table S2). All data were reported on a dry weight $(\mathrm{dw})$ basis. Except for UV-320 and UV-PS, seven other BZTs could be positively identified in the sludge samples with concentrations in the range from 0.96 to $28.4 \mu \mathrm{g} / \mathrm{g}$. Since UV$\mathrm{P}, \mathrm{UV}-329, \mathrm{UV}-234, \mathrm{UV}-326$, and UV-328 were detected in almost all of the samples, their usage could be considered to be extensive in China. UV-234 was the most dominant BZT analogue, with a median concentration of $116 \mathrm{ng} / \mathrm{g}$, which constitute $0.8-69.4 \%$ (average $27.2 \%$ ) of total BZT concentrations ( $\sum \mathrm{BZT}$ ). This was successively followed by UV-329 (average 24.3\%), UV-326 (average 22.2\%), UV-328 (average $17.7 \%$ ), and UV-P (average 6.6\%), with median concentrations of $66.8,67.8,57.3$, and $20.6 \mathrm{ng} / \mathrm{g}$, respectively. Low detected frequency $(23 / 60)$ was found for UV-327 with an average concentration of $7.41 \mathrm{ng} / \mathrm{g}$. UV-350 was only detectable in four cities in Shandong Province, which indicated that this compound might only have limited production and usage in China.

A few studies have investigated the levels and composition patterns of BZTs in environmental matrices, and the reported contamination patterns varied substantially among different regions. A study on the marine environment in the Japanese Ariake Sea showed that UV-326, UV-327, and UV-328 were the most frequently detected BZTs with comparable concentrations in the river mouth sediments, whereas UV-320 content was much lower due to its discontinued usage. ${ }^{19}$ Carpinteiro and co-workers investigated wastewater and indoor dust samples in human living environments such as private houses and car cabins in Spain and also reported that UV-326, UV-P, UV-328, and UV-327 were all major BZT contaminants. ${ }^{18,37}$ Furthermore, it was found that UV-328 and UV-326 were dominant in river sediment in northern China and U.S. waters. ${ }^{20}$ UV-328 and UV-234 were found to be the dominant analogues in the sediments of Japanese rivers and lakes, while contributions from other BZTs were almost negligible. ${ }^{38}$ As illustrated in Figure 3, the BZT concentration profile in our investigated sewage sludge samples was similar to those collected in northern China and U.S. waters, ${ }^{20}$ in which UV328 and UV-326 showed relative higher concentrations, successively followed by UV-P and UV-327, while UV-320 was not detected. Moreover, the observed composition pattern in the sludge samples in our work was also quite consistent with the global BZT production volumes. According to the OECD and U.S. EPA HPV databases, ${ }^{4,5}$ production volumes of UV328, UV-329, and UV-234 were between 1 and 10 million lbs and those of UV-326 and UV-P were in the range from 50000 to 1 million lbs, while UV-327 was produced at less than 50000 lbs, and no relevant data could be found for other BZT chemicals due to low production volumes.

It was noted that UV-329, UV-350, and UV-234 were also detected at high levels in the sludge samples, and their combined concentrations constituted for $51.4 \%$ of $\sum$ BZT. The occurrence of UV-329 and UV-350 is interesting, as these two compounds are isomers of UV-320, which is a priority monitoring chemical that has been banned by the Japanese Government for its persistent, bioaccumulative, and toxic properties. $^{25}$ Currently, little information could be found concerning the environmental fate and potential toxic behaviors of UV-329 and UV-350 in environment matrices and biota. However, on the basis of model calculations (U.S. EPA EPI Suite V4.1 ${ }^{39}$ ), it was found that UV-329 and UV-350 share much similar physicochemical properties with UV-320, or even had higher predicted bioaccumulation factors ( $\log$ BCF of 3.77, 


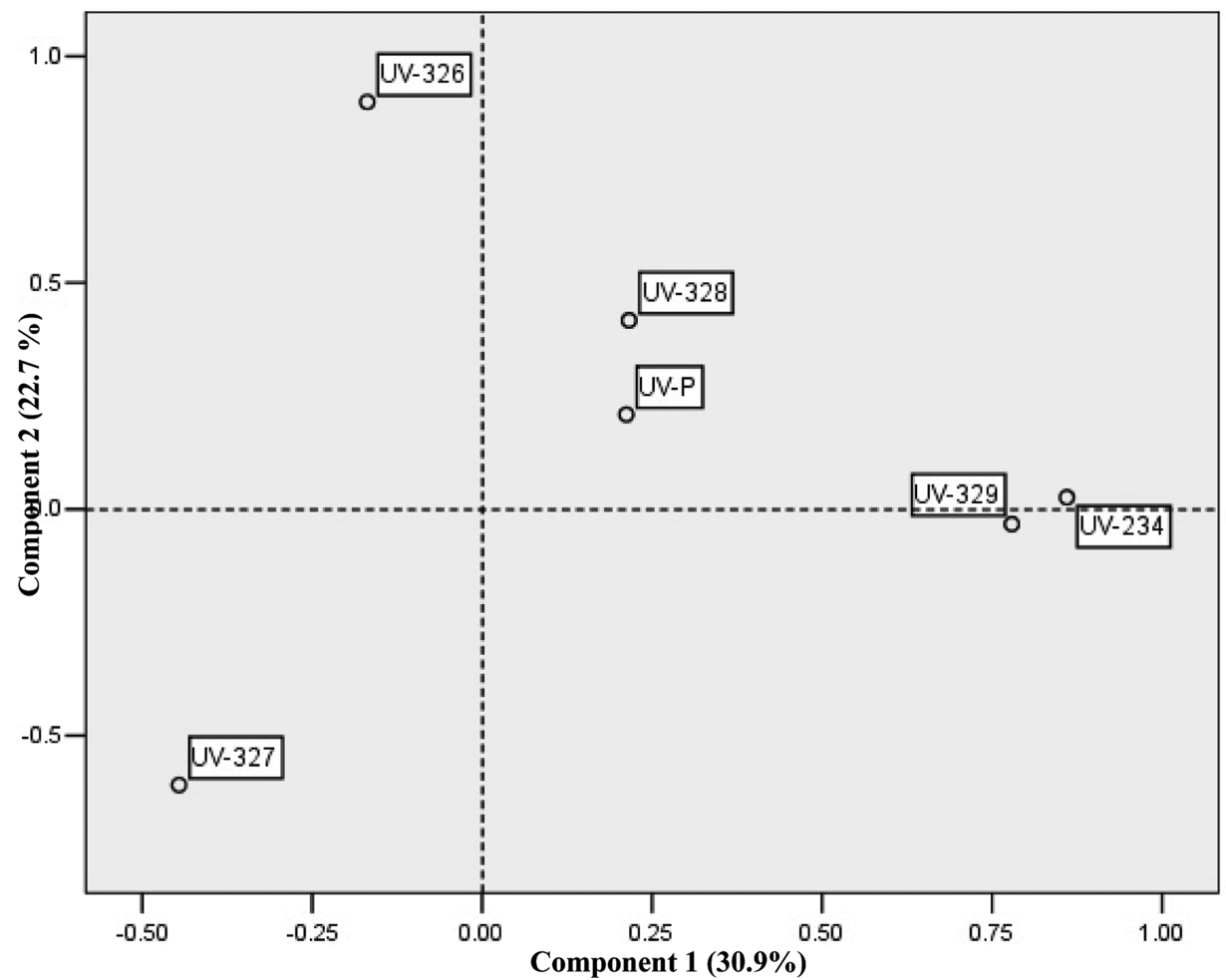

Figure 4. The loading plots of benzotriazole analogue concentrations in the sewage sludge samples from the principal component analysis.

3.83, and 3.49 for UV-329, UV-350, and UV-320, respectively) due to their branched-chain substituents. The presence of UV234 at high concentrations in the sludge samples might also be of high interest due to its usage as an additive in food packaging material $^{40}$ and potential bioaccumulation abilities (log BCF $=$ 3.57). Repeated-dose toxicity data showed that UV-234 could also cause histopathological changes such as liver weight increase and a slight to moderate hypertrophy of hepatocytes, and the NOAEL was set at $50 \mathrm{mg} / \mathrm{kg}$. ${ }^{41}$

Multivariate Analysis and Influence Factors. Except for UV-350, most of the BZTs were detected in the sewage sludge from the different Chinese provinces. No obvious geographic trend was associated with the concentration distribution pattern of the BZT analogues, indicating the universality of BZT usages and contamination in China. Principal component analysis was performed to examine the factors that might affect the BZT concentrations in the sludge samples. Three principal components (PCs) with eigenvalues greater than 1 contributed to a total of $70.5 \%$ of the cumulative variances. Figures 4 and S2 (Supporting Information) illustrate the loading and score plots of the first two principal components, which accounted for $53.6 \%$ of the data variability. In the loading plot, factor 1 was strongly associated with UV-234 $(R=0.860)$ and UV-329 $(R=$ $0.779)$, factor 2 was predominated by UV-326 $(R=0.899)$, whereas the third component had high correlation with UV-328 $(R=0.704)$. Figure 4 and Table 1 show that UV-234 was correlated with UV-329 $(R=0.419, P<0.01)$, and UV-328 was associated with UV-326 $(R=0.291, P<0.05)$. Principal component biplot, shown in the Supporting Information (Figure S1), further explained the relationship between the BZT concentration ratios. For example, no obvious correlations were observed in the UV-P/UV-327 and UV-328/UV-327 ratios, as the rays linking UV-P/UV-327 and UV-328/UV-327 were nearly at right angles. However, the short links between
Table 1. Pearson's Correlation Matrix for the Detected BZT Concentrations and WWTP Daily Processing Volume

$\begin{array}{lllllll} & \text { UV-P } & \text { UV-329 } & \text { UV-234 } & \text { UV-326 } & \text { UV-328 } & \text { UV-327 } \\ \text { UV-329 } & 0.244 & & & & & \\ \text { UV-234 } & 0.096 & 0.419^{b} & & & & \\ \text { UV-326 } & 0.010 & -0.098 & -0.050 & & & \\ \text { UV-328 } & -0.053 & -0.016 & 0.185 & 0.291^{c} & & \\ \text { UV-327 } & -0.186 & -0.325^{c} & -0.326^{c} & -0.325^{c} & -0.014 & \\ \begin{array}{c}\text { WWTP } \\ \text { processing }\end{array} & 0.320^{c} & 0.302^{c} & 0.228 & 0.025 & 0.254^{c} & 0.192 \\ \text { volume }^{a} & & & & & & \\ \text { All } & & & & & & \end{array}$

${ }^{a}$ All data were log-transformed. ${ }^{b}$ Represent significant correlation at the 0.01 level. ${ }^{c}$ Represent significant correlation at the 0.05 level.

the vertex of UV-326 and UV-328 and the vertex of UV-P, UV329 , and UV-234 rays indicated that relationships existed between these BZT analogues. These also suggested that UV326/UV-328 and UV-P/UV-329 concentration ratios were relatively constant in the sludge samples. Strong correlation between concentrations of different environmental contaminants could suggest common sources and/or similar environmental fates. The separated groups of BZT analogues might thus further imply their diverse usage in commercial products and different environmental release sources in China.

Table S2 of the Supporting Information summarizes some basic information of the investigated WWTPs, such as daily wastewater processing volume and biological treatment techniques, which were mainly grouped into anaerobicanoxic-oxic (AAO), oxidation ditch (OD), anoxic/oxic (AO), and sequencing batch reactor (SBR) activated sludge processes. The loading plots of PCA in Figure S2 (Supporting Information) were grouped by treatment techniques to further visualize potential relationships. No obvious relationship was found between the log-transformed BZT analogue concen- 

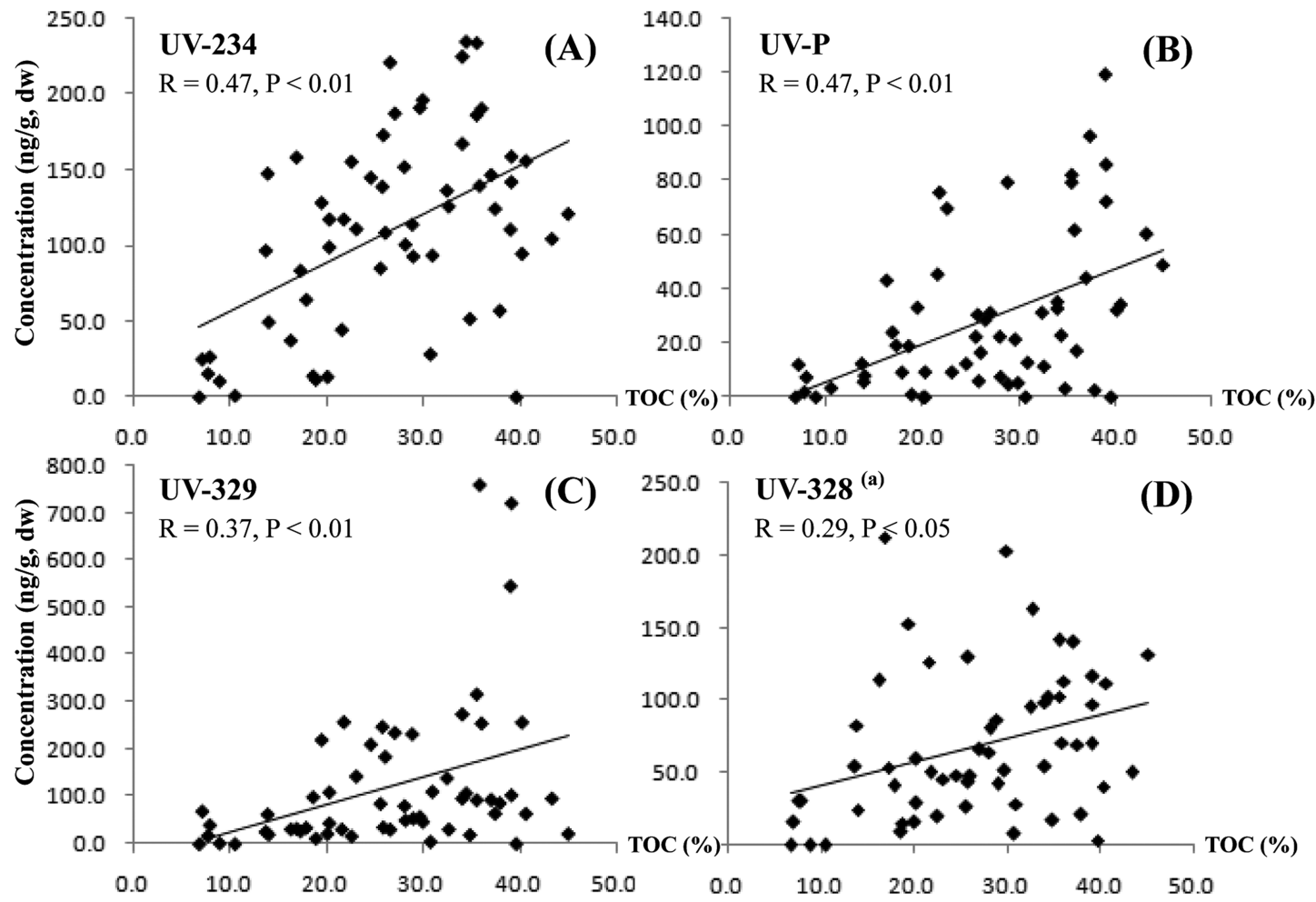

Figure 5. Correlations between concentrations of UV-P (A), UV-234 (B), UV-329 (C), and UV-328 (D) and total organic carbon (TOC) content in the sewage sludge samples. (a) The extreme value for UV-328 concentration in HB-1 was excluded in the linear regression analysis.

trations and the different sludge treatment processes. However, Table 1 shows that WWTP daily processing volumes were moderately correlated with UV-P $(R=0.320)$, UV-329 $(R=$ $0.302)$, and UV-328 $(R=0.254)$ concentrations, but no such relationships were found for other BZTs. The correlation between concentrations of hydrophobic environmental contaminants (e.g., polybrominated diphenyl ethers, PBDEs) and WWTP characteristics (e.g., processing capacity and serving population) were not always observed in other studies. For example, PBDEs levels were reported to be higher in larger WWTPs in Europe but were not considered to be related with processing capacity and serving population in North America and China. ${ }^{42,43}$

As the investigated BZTs have similar molecular structures which only differed by the different alkyl substituents, their hydrophobic properties, transport behaviors, and biodegradation potentials can also be perceived to be quite similar. Model calculations (STPWIN32 in EPI Suite V4.1, using the default setting for chemical half-lives of $10000 \mathrm{~h}$ as worse-case scenario) showed that there are differences in sludge adsorption efficiency for relatively lower hydrophobic analogues such as UV-P $\left(\log K_{\mathrm{ow}}=4.31\right.$, adsorption efficiency $\left.=45 \%\right)$ and more hydrophobic ones such as UV-329 $\left(\log K_{\mathrm{ow}}=6.21\right.$, adsorption efficiency $=92 \%)$. However, in Figure 5, UV-P, UV-329, UV234, and UV-328 all showed similar linear correlation coefficients with total organic carbon (TOC) content in the sludge samples. This might imply that other chemical mechanisms, such as planar-like configuration and degradation, could also affect the sludge adsorption capability besides the hydrophobicity of the BZT chemicals. From the results, it can be considered that sewage sludge could be used as an appropriate environmental matrix for monitoring the occurrence and contamination level of the selected BZT analogues in the urban environment.
Predicted Fate of Commercial BZT Analogues in the Environment. Some BZTs have been detected at high concentrations in biological species ${ }^{19}$ and various environmental matrixes, such as estuary sediment $\operatorname{cores}^{21,23}$ and sewage sludge under different biological treatment conditions, showing their persistence and distinct release pathways from anthropogenic sources to the environment. Thus more attention should be focused on the potential occurrence of other commercial BZT analogues in the environment and on the environmental fate of BZT parent compounds and their major transformation products.

Besides the widely used aromatic and aliphatic substituted BZT in this work, other homologues with carboxylate substituent such as UV-8M (Eversorb 8M, CAS Registry No. 84268-33-7) and UV-384 (CAS Registry No. 127519-17-9) shown in Figure 1 are also found in the OECD and U.S. EPA HPV list. These compounds are particularly used in automobile and other aqueous coatings with production volumes of 1-10 million lbs per year. However, limited information on the potential environmental occurrence and fate of these carboxylate substituted analogues can be found due to a lack of laboratory standards. We therefore used different quantitative structure-property relationship (QSPR) models to investigate the environmental fate at a screening level for selected BZTs in this study. BIOWIN3 is a biodegradation model that is frequently used to estimate the ultimate degradation half-lives of chemicals. ${ }^{44}$ On the basis of the calculations (EPI suite V4.1), the BIOWIN3 scores ranged from 2.68 (UV-P) to 1.83 (UV-327), indicating that the expected BZT total degradation time was from "weeks to months" to "months" levels. When the BIOWIN output values were applied in the STPWIN32 to simulate the effect of degradation half-lives in the WWTP treatment process, it was revealed that the biotransformation process of BZTs con- 

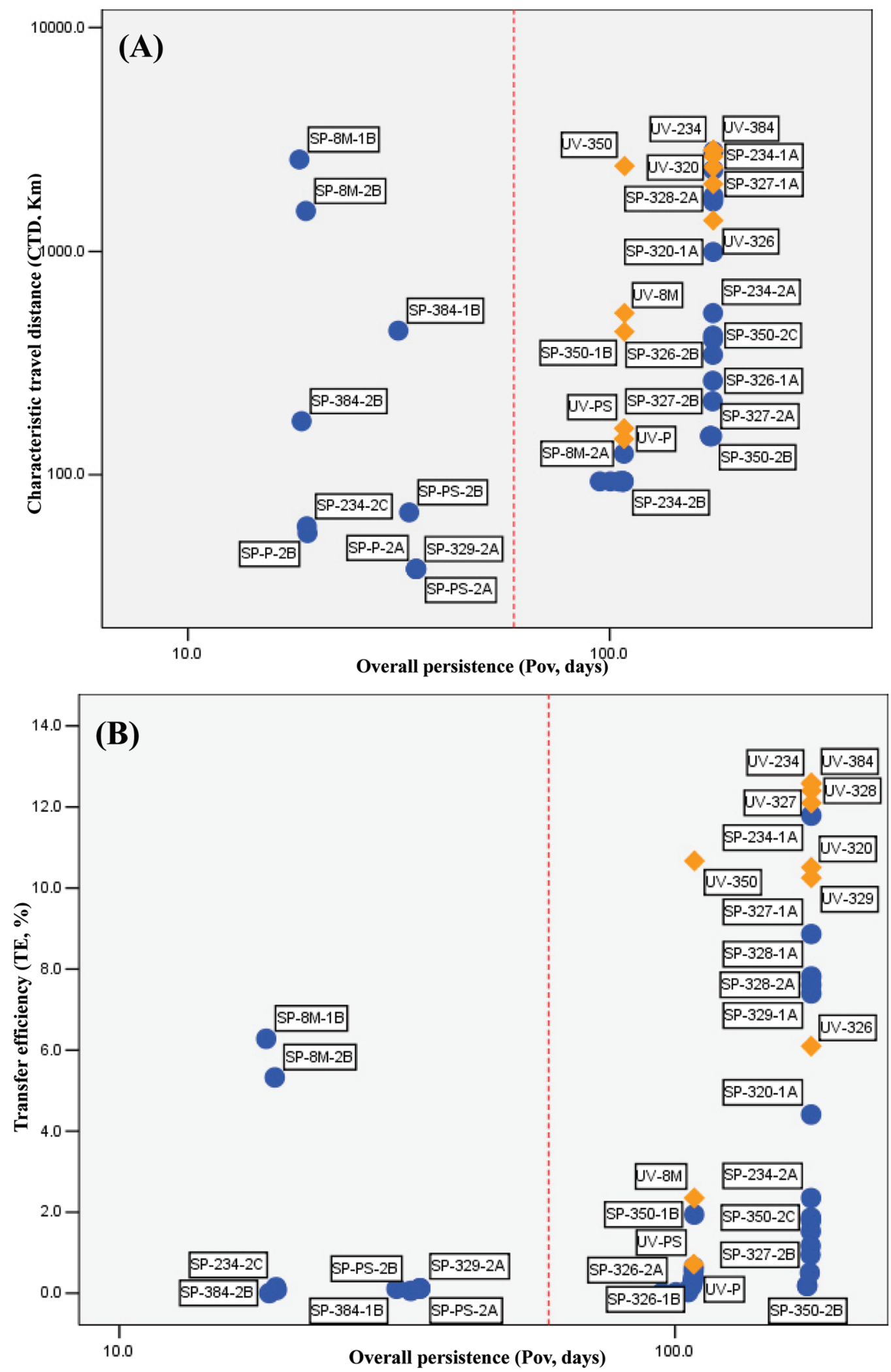

Figure 6. Overall persistence (Pov), characteristic travel distance (CTD), and transfer efficiency (TE) values calculated by the OECD Pov-LRTP tool for the BZTs and their potential transformation products generated by the UM-PPS framework (A, Pov vs CTD; B, Pov vs TE. $\bullet$ and $\bullet$ represent the BZT analogue and corresponding transformation products, respectively. Red lines represent the degradation half-life threshold of 60 days.).

stituted about $26-47 \%$ of the total BZT removal, which was comparable to that of the dominant sludge adsorption approach $(33-72 \%)$. This is consistent with the recently reported fate of aromatic musks and other UV filters in WWTPs, where most of the chemicals were removed during the processes, and sorption onto solids and biodegradation were the two main removal 
pathways. $^{45}$ However, as benzotriazole chemicals are not included into the training set of the BIOWIN package, the predicted results might have large uncertainties. More detailed laboratory and field studies are recommended to further assess the effect of biodegradation on the BZT removal efficiency in the WWTPs.

In addition, the University of Minnesota Pathway Prediction System (UM-PPS) and OECD overall persistence and longrange transport potential fugacity screening tool (Pov-LRTP tool) were respectively applied to predict potential transformation pathways and total persistency in a multimedia evaluative environment. ${ }^{46,47}$ UM-PPS is a well-established microbial catabolic reaction database that recognizes the substructure of a chemical and predicts transformation products (TPs) by matching biotransformation rules. The BZT degradation prediction procedures followed the established criteria published elsewhere to simplify combinatorial explosion routes. ${ }^{48}$ Essential environmental relevant parameters, such as octanol-water partition coefficient $\left(K_{\mathrm{ow}}\right)$, air-water partition coefficient $\left(K_{\mathrm{aw}}\right)$, and half-lives in air, water, and soil for BZTs and their TPs were obtained by KOWWIN, KOAWIN, and Level III Fugacity Model in the EPI Suite V4.1 and introduced into the Pov-LRTP tool. As shown in the Supporting Information (Schemes S1-S11), BZT analogues with different branched-chain substituent displayed distinct plausible transformation pathways in aerobic conditions. For carboxylatesubstituted BZTs such as UV-8M and UV-384, the carboxylate group might be more likely to break apart to form smaller carboxylic TPs. Hydrolysis could occur for aromatic and aliphatic substituted BZTs, and hydroxyl and aldehyde groups could be generated to form primary and secondary TPs. Hydrolytic processes might also be possible for chlorinecontaining BZTs such as UV-326, which could even lead to the breakdown of the benzotriazole subgroups. Besides, the phenol substructure of the BZTs was similar to those of other phenolic antioxidants such as butylated hydroxytoluene (BHT). Thus, the well-known oxidation pathway of BHT to form phenoxyl radical and $p$-quinone metabolites as mentioned elsewhere might also be possible for BZT chemicals. ${ }^{49}$

However, when the physicochemical coefficients (Supporting Information, Table S3) of the BZTs and TPs were introduced into the Pov-LRTP tool, most of the BZTs and their major TPs exceeded the 60-day threshold with overall persistent half-lives ranging from 94.8 to 174 days, with the exception of the secondary TPs of UV-P, UV-PS, and UV-329 and other smaller molecular degradation products (Figure 6 and Supporting Information, Table S3). This implied that many BZT UV stabilizers could have high environmental persistence, and various BZT degradation products might also be present in the environment. Moreover, the calculated characteristic travel distance values exceeded $100 \mathrm{~km}$ for almost all of the BZTs and relevant TPs (Figure 6A), suggesting a potential wide distribution of these chemicals on a continental scale after point source release. However, as seen in Figure 6B, low transfer efficiency $(<5 \%)$ from air deposition mass flux was found for most of the TPs as a result of increased hydrophilic characteristics during the BZT degradation process. This might imply their restricted distribution mainly in aquatic systems.

In this work, seven benzotriazole UV stabilizers were identified in most of the 60 sewage sludge samples collected from different wastewater treatment plants, suggesting the prevalent usage of BZT-containing products and widespread contamination in various parts of China. Further studies are needed to discern the release pathways and spatial and temporal distributions and to investigate if additional BZT analogues also could be present in the environment. As the screening models implied that BZTs and their potential transformation products might have overall persistent properties, more detailed research is warranted regarding the fate of BZTs during wastewater treatment procedures and microbial degradation processes and the impact of overall persistence to the long-range transport and global distribution potentials.

\section{ASSOCIATED CONTENT}

\section{Supporting Information}

Additional information as noted in the text. This material is available free of charge via the Internet at http://pubs.acs.org.

\section{AUTHOR INFORMATION}

\section{Corresponding Author}

*Phone: 8610-6284-9334; fax: 8610-6284-9179; e-mail: gbjiang@rcees.ac.cn.

Notes

The authors declare no competing financial interest.

\section{ACKNOWLEDGMENTS}

This work was jointly supported by the National Basic Research Program of China (2009CB421605) and the National Natural Science Foundation $(20677068,20897011)$.

\section{REFERENCES}

(1) Muir, D. C. G.; Howard, P. H. Are there other persistent organic pollutants? A challenge for environmental chemists. Environ. Sci. Technol. 2006, 40 (23), 7157-7166.

(2) Howard, P. H.; Muir, D. C. G. Identifying new persistent and bioaccumulative organics among chemicals in commerce. Environ. Sci. Technol. 2010, 44 (7), 2277-2285.

(3) Czub, G.; Wania, F.; Mclachlan, M. S. Combining long-range transport and bioaccumulation considerations to identify potential arctic contaminants. Environ. Sci. Technol. 2008, 42 (10), 3704-3709.

(4) U.S. Environmental Protection Agency. Available online at http://www.epa.gov/hpv/ (accessed on July 26, 2011).

(5) Organization for Economic Co-operation and Development. Available online at http://webnet.oecd.org/hpv/ui/Default.aspx (accessed on July 26, 2011).

(6) Richardson, S. D.; Ternes, T. A. Water analysis: Emerging contaminants and current issues. Anal. Chem. 2011, 83 (12), 46144648.

(7) Giokas, D. L.; Salvador, A.; Chisvert, A. UV filters: From sunscreens to human body and the environment. TrAC, Trends Anal. Chem. 2007, 26 (5), 360-374.

(8) Diaz-Cruz, M. S.; Barcelo, D. Chemical analysis and ecotoxicological effects of organic UV-absorbing compounds in aquatic ecosystems. TrAC, Trends Anal. Chem. 2009, 28 (6), 708-717.

(9) Poiger, T.; Buser, H. R.; Balmer, M. E.; Bergqvist, P. A.; Muller, M. D. Occurrence of UV filter compounds from sunscreens in surface waters: Regional mass balance in two Swiss lakes. Chemosphere 2004, 55 (7), 951-963.

(10) Balmer, M. E.; Buser, H. R.; Muller, M. D.; Poiger, T. Occurrence of some organic UV filters in wastewater, in surface waters, and in fish from Swiss lakes. Environ. Sci. Technol. 2005, 39 (4), 953962.

(11) Fent, K.; Zenker, A.; Rapp, M. Widespread occurrence of estrogenic UV-filters in aquatic ecosystems in Switzerland. Environ. Pollut. 2010, 158 (5), 1817-1824.

(12) Sánchez-Brunete, C.; Miguel, E.; Albero, B.; Tadeo, J. L. Analysis of salicylate and benzophenone-type UV filters in soils and sediments by simultaneous extraction cleanup and gas chromatog- 
raphy-mass spectrometry. J. Chromatogr. A 2011, 1218 (28), 42914298.

(13) Li, W. H.; Ma, Y. M.; Guo, C. S.; Hu, W.; Liu, K. M.; Wang, Y. Q.; Zhu, T. Occurrence and behavior of four of the most used sunscreen UV filters in a wastewater reclamation plant. Water Res. 2007, 41 (15), 3506-3512.

(14) Plagellat, C.; Kupper, T.; Furrer, R.; de Alencastro, L. F.; Grandjean, D.; Tarradellas, J. Concentrations and specific loads of UV filters in sewage sludge originating from a monitoring network in Switzerland. Chemosphere 2006, 62 (6), 915-925.

(15) Janjua, N. R.; Mogensen, B.; Andersson, A. M.; Petersen, J. H.; Henriksen, M.; Skakkebaek, N. E.; Wulf, H. C. Systemic absorption of the sunscreens benzophenone-3, octyl-methoxycinnamate, and 3-(4methyl-benzylidene) camphor after whole-body topical application and reproductive hormone levels in humans. J. Invest. Dermatol. 2004, 123 (1), 57-61.

(16) Suzuki, T.; Kitamura, S.; Khota, R.; Sugihara, K.; Fujimoto, N.; Ohta, S. Estrogenic and antiandrogenic activities of 17 benzophenone derivatives used as UV stabilizers and sunscreens. Toxicol. Appl. Pharmacol. 2005, 203 (1), 9-17.

(17) Schlumpf, M.; Cotton, B.; Conscience, M.; Haller, V.; Steinmann, B.; Lichtensteiger, W. In vitro and in vivo estrogenicity of UV screens. Environ. Health. Persp. 2001, 109 (3), 239-244.

(18) Carpinteiro, I.; Abuin, B.; Rodriguez, I.; Ramil, M.; Cela, R. Pressurized solvent extraction followed by gas chromatography tandem mass spectrometry for the determination of benzotriazole light stabilizers in indoor dust. J. Chromatogr. A 2010, 1217 (24), 3729-3735.

(19) Nakata, H.; Murata, S.; Filatreau, J. Occurrence and concentrations of benzotriazole UV stabilizers in marine organisms and sediments from the Ariake Sea, Japan. Environ. Sci. Technol. 2009, 43 (18), 6920-6926.

(20) Zhang, Z. F.; Ren, N. Q.; Li, Y. F.; Kunisue, T.; Gao, D. W.; Kannan, K. Determination of benzotriazole and benzophenone UV filters in sediment and sewage sludge. Environ. Sci. Technol. 2011, 45 (9), 3909-3916.

(21) Latimer, J. S.; Quinn, J. G. Historical trends and current inputs of hydrophobic organic compounds in an urban estuary: The sedimentary record. Environ. Sci. Technol. 1996, 30 (2), 623-633.

(22) Lopez-Avila, V.; Hites, R. A. Organic compounds in an industrial wastewater. Their transport into sediments. Environ. Sci. Technol. 1980, 14 (11), 1382-1390.

(23) Reddy, C. M.; Quinn, J. G.; King, J. W. Free and bound benzotriazoles in marine and freshwater sediments. Environ. Sci. Technol. 2000, 34 (6), 973-979.

(24) Pruell, R. J.; Hoffman, E. J.; Quinn, J. G. Total hydrocarbons, polycyclic aromatic-hydrocarbons and synthetic organic-compounds in the hard shell clam, Mercenaria mercenaria, purchased at commercial seafood stores. Mar. Environ. Res. 1984, 11 (3), 163-181.

(25) Ministry of Economy, Trade and Industry, Japan. Available online at http://www.meti.go.jp/committee/materials/downloadfiles/ g60705a03j.pdf (accessed on July 26, 2011).

(26) Yamano, T.; Shimizu, M.; Noda, T. Relative elicitation potencies of seven chemical allergens in the guinea pig maximization test. J. Health Sci. 2001, 47 (2), 123-128.

(27) Hirata-Koizumi, M.; Watari, N.; Mukai, D.; Imai, T.; Hirose, A.; Kamata, E.; Ema, M. A 28-day repeated dose toxicity study of ultraviolet absorber 2-(2'-hydroxy-3',5'-di-tert-butylphenyl)benzotriazole in rats. Drug. Chem. Toxicol. 2007, 30 (4), 327-341.

(28) U.S. Environmental Protection Agency. Available at http:// iaspub.epa.gov/oppthpv/quicksearch.display?pChem=100705 (accessed on July 26, 2011).

(29) U.S. Environmental Protection Agency. Available at http:// iaspub.epa.gov/oppthpv/quicksearch.display?pChem=100707 (accessed on July 26, 2011).

(30) Kim, J.; Chang, K.; Isobe, T.; Tanabe, S. Acute toxicity of benzotriazole ultraviolet stabilizers on freshwater crustacean (Daphnia pulex). J. Toxicol. Sci. 2011, 36 (2), 247-251.
(31) Oberg, K.; Warman, K.; Oberg, T. Distribution and levels of brominated flame retardants in sewage sludge. Chemosphere 2002, 48 (8), 805-809.

(32) Buser, H. R.; Balmer, M. E.; Schmid, P.; Kohler, M. Occurrence of UV filters 4-methylbenzylidene camphor and octocrylene in fish from various swiss rivers with inputs from wastewater treatment plants. Environ. Sci. Technol. 2006, 40 (5), 1427-1431.

(33) Gago-Ferrero, P.; Díaz-Cruz, M. S.; Barceló, D. Occurrence of multiclass UV filters in treated sewage sludge from wastewater treatment plants. Chemosphere 2011, 84 (8), 1158-1165.

(34) Wick, A.; Marincas, O.; Moldovan, Z.; Ternes, T. A. Sorption of biocides, triazine and phenylurea herbicides, and UV-filters onto secondary sludge. Water Res. 2011, 45 (12), 3638-3652.

(35) Qiu, X. H.; Hites, R. A. Dechlorane plus and other flame retardants in tree bark from the Northeastern United States. Environ. Sci. Technol. 2008, 42 (1), 31-36.

(36) Howel, D. Multivariate data analysis of pollutant profiles: PCB levels across Europe. Chemosphere 2007, 67, 1300-1307.

(37) Carpinteiro, I.; Abuin, B.; Rodriguez, I.; Cela, R.; Ramil, M. Headspace solid-phase microextraction followed by gas chromatography tandem mass spectrometry for the sensitive determination of benzotriazole UV stabilizers in water samples. Anal. Bioanal. Chem. 2010, 397 (2), 829-839.

(38) Kameda, Y.; Kimura, K.; Miyazaki, M. Occurrence and profiles of organic sun-blocking agents in surface waters and sediments in Japanese rivers and lakes. Environ. Pollut. 2011, 159 (6), 1570-1576.

(39) U.S. Envrionmental Protection Agency. Exposure Assessment Tools and Models, Estimation Program Interface (EPI) Suite, V 4.1; U.S. Environmental Protection Agency, Exposure Assessment Branch: Washington, DC, 2011.

(40) European Commission. Available online at http://ec.europa.eu/ food/food/chemicalsafety/foodcontact/eu_substances_en.pdf (accessed at July 26, 2011).

(41) U.S. Environmental Protection Agency. Available at http:// iaspub.epa.gov/oppthpv/quicksearch.display?pChem $=100708$ (accessed on July 26, 2011).

(42) Hale, R. C.; Alaee, M.; Manchester-Neesvig, J. B.; Stapleton, H. M.; Ikonomou, M. G. Polybrominated diphenyl ether flame retardants in the North American environment. Environ. Int. 2003, 29 (6), 771779.

(43) Wang, Y. W.; Zhang, Q. H.; Lv, J. X.; Li, A.; Liu, H. X.; Li, G. G.; Jiang, G. B. Polybrominated diphenyl ethers and organochlorine pesticides in sewage sludge of wastewater treatment plants in China. Chemosphere 2007, 68 (9), 1683-1691.

(44) Boethling, R. S.; Howard, P. H.; Meylan, W.; Stiteler, W.; Beauman, J.; Tirado, N. Group-contribution method for predicting probability and rate of aerobic biodegradation. Environ. Sci. Technol. 1994, 28 (3), 459-465.

(45) Kupper, T.; Plagellat, C.; Brändli, R. C.; de Alencastro, L. F.; Grandjean, D.; Tarradellas, J. Fate and removal of polycyclic musks, UV filters and biocides during wastewater treatment. Water Res. 2006, 40 (14), 2603-2612.

(46) Ellis, L. B. M.; Gao, J.; Fenner, K.; Wackett, L. P. The University of Minnesota pathway prediction system: Predicting metabolic logic. Nucleic Acids Res. 2008, 36 (2), W427-W432.

(47) Organization for Economic Co-operation and Development. Available online at http://www.oecd.org/LongAbstract/0,3425,en 2649_34379_40718985_119669_1_1_1,00.html (accessed on July $26,2011)$.

(48) Ng, C. A.; Scheringer, M.; Fenner, K.; Hungerbuhler, K. A framework for evaluating the contribution of transformation products to chemical persistence in the environment. Environ. Sci. Technol. 2011, 45 (1), 111-117.

(49) Thompson, D. C.; Cha, Y. N.; Trush, M. A. The peroxidasedependent activeation of butylated hydroxyanisole and butylated hydroxytoluene (BHT) to reactive intermediates. J. Biol. Chem. 1989, 264 (7), 3957-3965. 